\title{
OBJECT-ORIENTED PROGRAMMING LANGUAGE SELECTION USING FUZZY AHP METHOD
}

\author{
BABAK DANESHVAR ROUYENDEGH (B.Erdebilli) \\ At1lim University \\ Ankara, Turkey \\ E-mail: babekd@atilim.edu.tr \\ SEYED HAJIR LESANI \\ At1lım University \\ Ankara, Turkey \\ E-mail: lesani.shajir@student.atilim.edu.tr
}

\begin{abstract}
A programming language is a notation for writing programs, which are specifications of computation of algorithm. The common view is programming languages make it easier to write programs for computers, now while that is true, what is often overlooked by language designers is that the other purpose, and maintain its primary purpose, is to make it easier for people to read and understand programs. A programming language decision inherently is a multi-criterion problem. In this context, we used Fuzzy Analytic Hierarchy Process (FAHP) for selecting the best object-oriented programming language. FAHP is a useful approach for evaluating complex multiple criteria alternatives involving subjective and uncertain judgment.

Keywords: Programming, programming language, FAHP, multi-criteria decision making.
\end{abstract}




\section{Introduction}

Multi- Criteria Decision-Making (MCDM) was introduced as a promising and important field of study in the early 1970's. Since then the number of contributions to theories and models, which could be used as a basis for more systematic and rational decision making with multiple criteria, has continued to grow at a steady rate.MCDM tries to find the best opinion from all of the feasible alternatives. In this study we tried to make a decision for the best object-oriented programming language. (Carlsson \& Full'er,1996).

A programming language is a notation for writing programs, which are specifications of computation of algorithm. The common view is programming languages make it easier to write programs for computers, now while that is true, what is often overlooked by language designers is that the other purpose, and maintain its primary purpose, is to make it easier for people to read and understand programs. Computer programming language is artificial languages designed to express computations that can be perform by a machine or a computer. A programming language decision inherently is a multi-criterion problem.

Fuzzy Multi-Criteria Decision Making (FMCDM) is an important branch of MCDM. FMCDM methods had been developed owing to the imprecision in assessing the relative importance of attributes and the performance ratings of alternatives with respect to attributes. Imprecision may arise from a variety of reasons: unquantifiable information, incomplete information, unobtainable information and partial ignorance. Conventional MCDM methods cannot effectively handle problems with such imprecise information. To resolve this difficulty, fuzzy set theory, first introduced by Zadeh (1965), has been popularly used. (Wu \& Cheng, 2008)

Additionally in many cases, the preference model of the human decision maker (DM) is uncertain, and it is relatively difficult for the DM to provide exact numerical values for the comparison ratios. (Wu \& Cheng, 2008)

Analytic Hierarchy Process (AHP) AHP is one of the most widely used MCDM methods. In this method, the DM performs pair-wise comparisons and, then, the pair-wise comparison matrix and the eigenvector are derived to specify the weights of each parameter in the problem. The weights guide the DM in choosing the superior alternative. (Erdebilli, 2008)

Fuzzy AHP (FAHP) is a synthetic extension of classical AHP method when the fuzziness of the decision maker is considered. Here, to accommodate the acknowledged possible uncertainty in the subjective judgments to be made, a FAHP approach is adopted. The earliest work in the FAHP appeared in van Laarhoven \& Pedrycz, (1983), which utilized triangular fuzzy numbers (TFNs) to model the pair wise comparisons made in order to elicit weights of preference of the decision alternatives considered. Since then, FAHPrelated developments have been repeatedly reported in the concomitant literature; e.g., spatial allocation within FAHP (Wu \& Lee \& Lin, (2004)

, the method of FAHP and fuzzy multiple-criteria decision-making (Hsieh \& Lu \& Tzeng, 2004), and deriving priorities from FAHP (Mikhailov, 2003). Therefore, in this paper, a hybrid model combining AHP and fuzzy set theory is proposed to avoid the pitfalls of 
each method and applied to select the best one among five object-oriented programming languages.

The aim of this paper is to use FAHP to select best programming language providing the most satisfaction for the criteria determined. The IT managers, staff and also students in Turkey were interviewed and the most important criteria taken into account students, IT Staff and IT Managers while they were selecting their programming languages were determined by a questionnaire.

\section{Literature Review}

Numerous authors have used AHP method to rank alternatives under fuzzy environment. We will summarize these studies below.

Lee (Lee \& Kang \& Hsu \& Hang, 2009) provided an analytical approach for supplier selection process in fuzzy environment. FAHP is established for evaluating suppliers according to their several aspects. Chen and $\mathrm{Qu}$ (Chen \& $\mathrm{Qu}, 2006)$, had proposed FAHP to evaluate the selection of logistics center location. Lee et al. (Lee \& Kang \& Change, 2009) developed a fuzzy multiple goal programming (FMGP) model to help downstream companies to select thin film transistor liquid crystal display (TFT-LCD) suppliers for cooperation. They applied FAHP first to analyze the importance of multiple factors by incorporating experts' opinion, and these factors include cost, yield and number of suppliers. They use multi-choice goal programming next to consider the limits of various resources and to formulate the constraints. Dagdeviren and Yuksel (2008), developed FAHP for behavior based safety management. Nagahanumaiah et al.,(2008), used FAHP to identify problem features for injection mold development. Duran and Aguilo (Duran \& Aguilo, 2008), used FAHP for machine-tool selection.

Felix et al. (2009) identified and discussed some of the important and critical decision criteria including risk factors for the development of an efficient system for global supplier selection. They discussed Fuzzy Extended Analytic Hierarchy Process (FEAHP) based methodology to tackle the different decision criteria like cost, quality, service performance and supplier's profile including the risk factors involved in the selection of global supplier in the current business scenario.

(Felix \& Cgab \& Niraj Kumar, 2009). Yang et al, proposed FAHP for vendor selection by integrated FMCDM techniques with independence and interdependence. (Yang \& Chiu \& Tzeng, 2008).

Rostamzadeh and Sofian provided a study for using 7Ms effectively to improve production systems performance with fuzzy decision making approach. (Rostamzadeh \& Sofian, 2011). In the study, first, the ratings and weights for $7 \mathrm{M}$ are evaluated and then MCDM model with FAHP and FTOPSIS is used. Cascales and Lamata, proposed FAHP for management maintenance processes where only linguistic information was available. (Cascales \& Lamata, 2008) Buyukozkan et al. had proposed FAHP method to evaluate elogistics-based strategic alliance partners. (Buyukozkan \& Feyzioglu \& Nebol, 2008). 
Jung provided an approach about integrated production-planning problem. FAHP and goal programming (GP) approach were used in this approach in order to solve this integrated production-planning problem (Jung, 2011). Bottani and Rizzi had used fuzzy logic to deal with vagueness of human thought and AHP to make a selection the most suitable dyad supplier/purchased item. (Bottani \& Rizzi, 2008)Tsai et al. used FAHP for market positioning and developing strategy in order to improve service quality in department stores. (Tsai \& Wu \& Liang, 2008) Chen et al. proposed combination of FAHP with multi-dimensional scaling in identifying the preference similarity of alternatives. (Chen \& Tzeng \& Ding, 2008)

Efendigil et al. (Efendigil \& Onut \& Kongar, 2008) provided a study about reverse logistics which plays an important role for customers since it provides warranty. Most of the companies outsource their reverse logistics from third-party logistics providers. In this study, the selection of third-party logistics providers is based on FAHP. Wu et al. (Wu \& Lin \& Chen, 2008) proposed FAHP for measurement non-profit organizational performance.

Zaerpour et al. (Zaerpour \& Rabbani \& Gharehgozli \& Tavakkoli-Moghaddam, 2008) provided a study about strategic decision-making structure to determine make-to-order (MTO) and make-to-stock (MTS) strategy. FAHP and SWOT are used in this study. Huang et al. (Huang \& Chu \& P. Y. \& Y. H., 2008) had applied FAHP to represent subjective expert judgments in government-sponsored R\&D project selection.

Wang et al. (Wang \& Kai \& Yee \& Diaz-Rainey, 2011) handle fuzzy logic, which is a popular method of incorporating uncertain parameters into the decision-making process, with AHP to form a selection (decision-making) model for different green initiatives in the fashion industry. Lee et al. (Lee \& Lee \& Pietrucha, 2008) had constructed FAHP to evaluate performance of IT department in the manufacturing industry in Taiwan.

El-Baz (El-Baz, 2011) provided a study about performance measurement in supply chain systems in the manufacturing environment. Fuzzy decision making approach was chosen for the proposed model in which AHP is used. The proposed model is tested numerically. Chang et al. (Chang \& Wu \& Lin \& Chen, 2008), used FAHP to evaluate and controlling silicon wafer slicing quality.

Chang and Wang (Chang \& Wang, 2008) had proposed consistent fuzzy preference relation in a comparison matrix. Weck et al. (Weck \& Klocke \& Schell \& Rüenauver, 1997) evaluated alternative production cycles using FAHP.

Kulak and Kahraman (Kulak \& Kahraman, 2005) used FAHP for multi-criteria selection among transportation companies. Kuo et al. (Kuo \& Chi \& Kao, 2002) integrated FAHP and artificial neural network for selecting convenience store location. Cheng (Cheng, 1996) proposed a new algorithm for evaluating naval tactical missile systems by the FAHP based on grade value of membership function. Zhu et al. (Zhu \& Jing \& Change, 1999) made a discussion on the extent analysis method and applications of FAHP.

\section{Research Design/Methodology}




\subsection{ANALYTIC HIERARCHY PROCESS (AHP)}

Saaty (1980) proposed AHP as a decision aid to help solve unstructured problems in economics, social and management sciences. AHP has been applied in a variety of contexts: from the simple everyday problem of selecting a school to the complex problems of designing alternative future outcomes of a developing country, evaluating political candidacy, allocating energy resources, and so on. The AHP enables the decision-makers to structure a complex problem in the form of a simple hierarchy and to evaluate a large number of quantitative and qualitative factors in a systematic manner under multiple criteria environment in confliction. (Cheng \& Yang \& Hwang, 1999)

The AHP is a general theory of measurement. It is used to derive relative priorities on absolute scale from both discrete and continuous paired comparisons in multilevel hierarchic structures. These comparisons may be taken from actual measurements or from a fundamental scale that reflects the relative strength of preferences and feelings. The AHP has a special concern with departure from consistency and the measurement of this departure, and with dependence within and between the groups of elements of its structure. It has found its widest applications in multi-criteria decision making in planning and resource allocation, and in conflict resolution. In its general form, the AHP is a nonlinear framework for carrying out both deductive and inductive thinking without use of the syllogism. This is made possible by taking several factors into consideration simultaneously, allowing for dependence and for feedback, and making numerical tradeoffs to arrive at a synthesis or conclusion. (Saaty \& Vargas, 2006)

The AHP techniques form a framework of the decisions that uses a one-way hierarchical relation with respect to decision layers. The hierarchy is constructed in the middle level(s), with decision alternatives at the bottom, as shown in Figure 2. The AHP method provides a structured framework for setting priorities on each level of the hierarchy using pair-wise comparisons that are quantified using a 1-9 scale as demonstrated in Table 1.

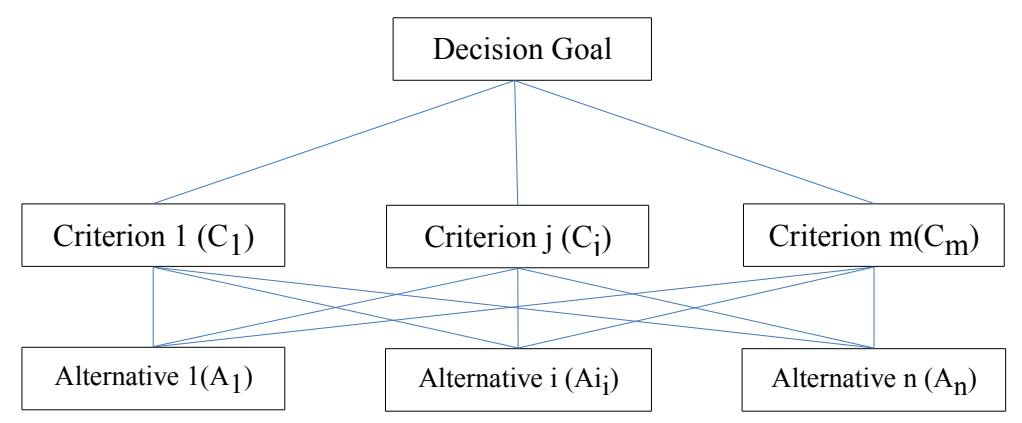

Figure.2. Hierarchy for a typical three-level MCDM problem. (Wang \& Liu \& Elhag, 2007)

\begin{tabular}{lcc}
\hline Importan Definition & \\
\hline & 5 & Washington, D. C. \\
$\begin{array}{l}\text { International Symposium of } \\
\text { the Analytic Hierarchy } \\
\text { Process }\end{array}$ & & June 29- July 2, 2014
\end{tabular}




\begin{tabular}{|c|c|c|}
\hline $\begin{array}{l}\text { ce } \\
\text { intensity }\end{array}$ & & Explanation \\
\hline 1 & $\begin{array}{l}\text { Equal } \\
\text { importance }\end{array}$ & Two activities contribute equally to the objective \\
\hline 3 & $\begin{array}{l}\text { Moderate } \\
\text { importance } \\
\text { of one over } \\
\text { another }\end{array}$ & $\begin{array}{l}\text { Experience and judgments slightly favor one } \\
\text { over another }\end{array}$ \\
\hline 5 & $\begin{array}{l}\text { Strong } \\
\text { importance } \\
\text { of one over } \\
\text { another }\end{array}$ & $\begin{array}{l}\text { Experience and judgment strongly favor one } \\
\text { over another }\end{array}$ \\
\hline 7 & $\begin{array}{l}\text { Very strong } \\
\text { importance } \\
\text { of one over } \\
\text { another }\end{array}$ & $\begin{array}{l}\text { Activity is strongly favored and its dominance is } \\
\text { demonstrated in practice }\end{array}$ \\
\hline 9 & $\begin{array}{l}\text { Extreme } \\
\text { importance } \\
\text { of one over } \\
\text { another }\end{array}$ & $\begin{array}{l}\text { Importance of one over another affirmed on the } \\
\text { highest possible order }\end{array}$ \\
\hline $2,4,6,8$ & $\begin{array}{l}\text { Intermediate } \\
\text { values }\end{array}$ & $\begin{array}{l}\text { Used to represent compromise between the } \\
\text { priorities listed above }\end{array}$ \\
\hline
\end{tabular}

Table 1.The 1-9 The Fundamental Scale of Absolute Numbers.

The application of the AHP to the complex problem usually involves four major steps (Cheng \& Yang \& Hwang, 1999):

1. Break down the complex problem into a number of small constituent elements and then structure the elements in a hierarchical form.

2. Make a series of pair wise comparisons among the elements according to a ratio scale.

3. Use the eigenvalue method to estimate the relative weights of the elements.

4. Aggregate these relative weights and synthesize them for the final measurement of given decision alternatives.

\subsection{FUZZY ANALYTIC HIERARCHY METHOD (FAHP)}


The fuzzy AHP technique can be viewed as an advanced analytical method developed from the traditional AHP. Despite the convenience of AHP in handling both quantitative and qualitative criteria of multi-criteria decision making problems based on decision maker's judgments, fuzziness and vagueness existing in many decision-making problems may contribute to the imprecise judgments of decision makers in conventional AHP approaches (Bouyssou \& Marchant \& Pirlot \& Perny \& Tsoukias \& Vincke, 2000). So, many researchers (Boender \& Graan \& Lootsma, 1989);(Buckley (a), 1985); (Buckley (b), 1985);(Chang, 1996);(Laarhoven \& Pedrycz, 1983); (Lootsma, 1997);(Ribeiro, 1996)) who have studied the fuzzy AHP which is the extension of Saaty's theory, have provided evidence that fuzzy AHP shows relatively more sufficient description of these kind of decision making processes compared to the traditional AHP methods.

In complex systems, the experiences and judgments of humans are represented by linguistic and vague patterns. Therefore, a much better representation of these linguistics can be developed as quantitative data, this type of data set is then refined by the evaluation methods of fuzzy set theory. On the other hand, the AHP method is mainly used in nearly crisp (non-fuzzy) decision applications and creates and deals with a very unbalanced scale of judgment. Therefore, the AHP method does not take into account the uncertainty associated with the mapping (Cheng \& Yang \& Hwang, 1999). The AHP's subjective judgment, selection and preference of decision-makers have great influence on the success of the method. The conventional AHP still cannot reflect the human thinking style. Avoiding these risks on performance, the FAHP, a fuzzy extension of AHP, was developed to solve the hierarchical fuzzy problems. (Ozdagoglu \& Ozdagoglu, 2007)

In this section, we modify the selection process procedure, as shown below:

We set up the Triangular Fuzzy Numbers (TFN's). Each expert makes a pair-wise comparison of the decision criteria and gives them relative scores. The inability of AHP to deal with the impression and subjectiveness in the pair-wise comparison process has been improved in the fuzzy AHP. Instead of a crisp value, the fuzzy AHP is a range of values to incorporate the decision-makers' uncertainty. This scale has been employed in Mikhailov (2003) fuzzy prioritization approach.

$\stackrel{\mathcal{L}}{(1)}=\left(l_{i}, m_{i}, u_{i}\right)$

$\stackrel{\prime}{G}_{1}=\left(l_{i}, m_{i}, u_{i}\right)$

$l_{i}=\left(l_{i 1} \otimes l_{i 2} \otimes \ldots \otimes l_{i k}\right)^{1 / k} \quad i=1,2, \ldots, k$

$m_{i}=\left(m_{i 1} \otimes m_{i 2} \otimes \ldots \otimes m_{i k}\right)^{1 / k} \quad i=1,2, \ldots, k$

$u_{i}=\left(u_{i 1} \otimes u_{i 2} \otimes \ldots \otimes u_{i k}\right)^{1 / k} \quad i=1,2, \ldots, k$

We set up the TFN's using the

AHP method based on the fuzzy numbers. Each expert makes a pair-wise comparison of the decision criteria and gives them relative scores: 
We establish the geometric fuzzy mean of the total row, using:

$$
i=1 \quad i=1 \quad i=1
$$

The fuzzy geometric mean of the fuzzy priority value is calculated with normalization priorities for factors using:

$$
\mathscr{W}=\frac{\&}{\%} / \%\left(l_{T}, m_{i}, u_{i}\right) /\left(\sum_{i=1}^{k} l_{i}, \sum_{i=1}^{k} m_{i}, \sum_{i=1}^{k} u_{i}\right)=\left[\frac{l_{i}}{\sum_{i=1}^{k} u_{i}}, \frac{m_{i}}{\sum_{i=1}^{k} m_{i}}, \frac{u_{i}}{\sum_{i=1}^{k} l_{i}}\right]
$$

Factors belonging to nine different $\alpha$-cut values are determined for the calculated $\alpha$. The fuzzy priorities will be applied for lower and upper limits for each $\alpha$ value:

$$
w i_{\alpha l}=\left(w i l_{\alpha l}, w i u_{\alpha l}\right) i=1,2, \ldots, k \quad l=1,2, \ldots, L
$$

Combine the entire upper values and the lower values separately, then divide them by the total sum of $\alpha$ value:

$$
\begin{aligned}
& W_{i l}=\frac{\sum_{i=1}^{L} \alpha\left(w_{i l}\right)_{l}}{\sum_{l=1}^{L} \alpha_{l}} \quad i=1,2, \ldots, k \quad l=1,2, \ldots, L \\
& W_{i u}=\frac{\sum_{i=1}^{L} \alpha\left(w_{i u}\right)_{l}}{\sum_{l=1}^{L} \alpha_{l}} \quad i=1,2, \ldots, k \quad l=1,2, \ldots, L
\end{aligned}
$$


The following formula is used in order to defuzzify by combining the upper limit value and the lower limit values using the optimism index $(\lambda)$

$w_{i d}=\lambda W_{i u}+(1-\lambda) W_{i l} \quad \lambda \in[0,1] \quad i=1,2, \ldots, k$

In this final stage the defuzzification values priorities are normalized using:

$$
W_{i n}=\frac{W_{i d}}{k} \quad i=1, \ldots, k
$$

\section{SELECTION CRITERIA AND ALTERNATIVES}

We have five programming language alternatives. These are $\mathrm{C}++, \mathrm{C \#}$, Java, Ruby, Python languages. These languages are explained briefly below.

$\mathrm{C}++$

$\mathrm{C}++$ was designed by Bjarne Stroustrup of AT\&T Bell Laboratories. The immediate ancestor of $\mathrm{C}++$ is a language called $\mathrm{C}$ with classes, also classes by Stroustrup in 1980. In turn, $\mathrm{C}$ with classes was heavily influenced by the languages $\mathrm{C}$ and Simula. $\mathrm{C}++$ is largely a superset of $\mathrm{C}$. However, in one sense, $\mathrm{C}++$ is simply a better $\mathrm{C}$, in that it provides type checking, overloaded functions, and many other improvements. Most importantly, $\mathrm{C}++$ adds object-oriented programming feature to C. An ANSI standard for $\mathrm{C}++$ was released. In addition to ANSI, $\mathrm{C}++$ has been standardized by British Standard Institute, the German National Standards Organization and International Standards Organization, as well as others. The ISO is current maintainer of the $\mathrm{C}++$ standards.

\section{C\#}

$\mathrm{C \#}$ programming refers to developing software using the $\mathrm{C \#}$ programming language on the .NET framework developed by Microsoft Corporation. C\# was developed in 2000 and 


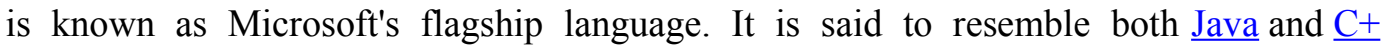
\pm . According to several engineers I have spoken with, it is preferred over both languages by many. C\# programming has quickly become a "hot" job skill. Programmers that have experience with $\mathrm{C \#}$ and related technologies are likely to be in high demand for the foreseeable future.

\section{Java}

In early 1990's, Sun Microsystems developed a programming language called Oak designed to program intelligent consumer electronic devices. The developers of Oak discovered that the name was already being used for another language, so they came up with the name Java while at a local coffee shop. The demand for intelligent consumer electronics was sluggish, but the World Wide Web exploded onto the scene in 1993, and Java was found to be good fit with this exciting new technology. Java was officially introduced by Sun in 1995 as a programming language to be used for applications distributed across computer networks. Now Java is used for all kinds of applications ranging from the Internet and large-scale enterprise applications to cell phones, pagers and PDAs. The Java development kit is offered free of cost: this factor allows potential users to try out the language with minimal start-up cost.

\section{Ruby}

Ruby is a dynamic, reflective, general purpose object-oriented programming language that combines syntax inspired by Perl with Smalltalk-like features. Ruby originated in Japan during the mid-1990s and was initially developed and designed by Yukihiro "Matz" Matsumoto. It was influenced primarily by Perl, Smalltalk, Eiffel, and Lisp.

Ruby supports multiple programming paradigms, including functional, object oriented, imperative and reflective. It also has a dynamic type system and automatic memory management; it is therefore similar in varying respects to Python, Perl, Lisp, Dylan, Pike, and $\underline{\mathrm{CLU}}$.

The standard 1.8.7 implementation is written in $\underline{\mathrm{C}}$, as a single-pass interpreted language. There is currently no specification of the Ruby language, so the original implementation is considered to be the de facto reference. As of 2010, there are a number of complete or upcoming alternative implementations of the Ruby language, including YARV, JRuby, Rubinius, IronRuby, MacRuby and HotRuby, each of which takes a different approach, with IronRuby, JRuby and MacRuby providing just-in-time compilation and MacRuby also providing ahead-of-time compilation. The official 1.9 branch uses YARV, as will 2.0 (development), and will eventually supersede the slower Ruby MRI.

\section{Python}

Python is a general-purpose high-level programming language whose design philosophy emphasizes code readability. Python aims to combine "remarkable power with very clear syntax", and its standard library is large and comprehensive. Its use of indentation for block delimiters is unusual among popular programming languages. 
Python supports multiple programming paradigms, primarily but not limited to object oriented, imperative and, to a lesser extent, functional programming. It features a fully dynamic type system and automatic memory management, similar to that of Scheme, Ruby, Perl, and Tcl. Like other dynamic languages, Python is often used as a scripting language, but is also used in a wide range of non-scripting contexts.

The reference implementation of Python (CPython) is free and open source software and has a community-based development model, as do all or nearly all of its alternative implementations. CPython is managed by the non-profit Python Software Foundation.

We have four steps for selecting the best alternative with using FAHP. These steps can be seen in Figure 3.

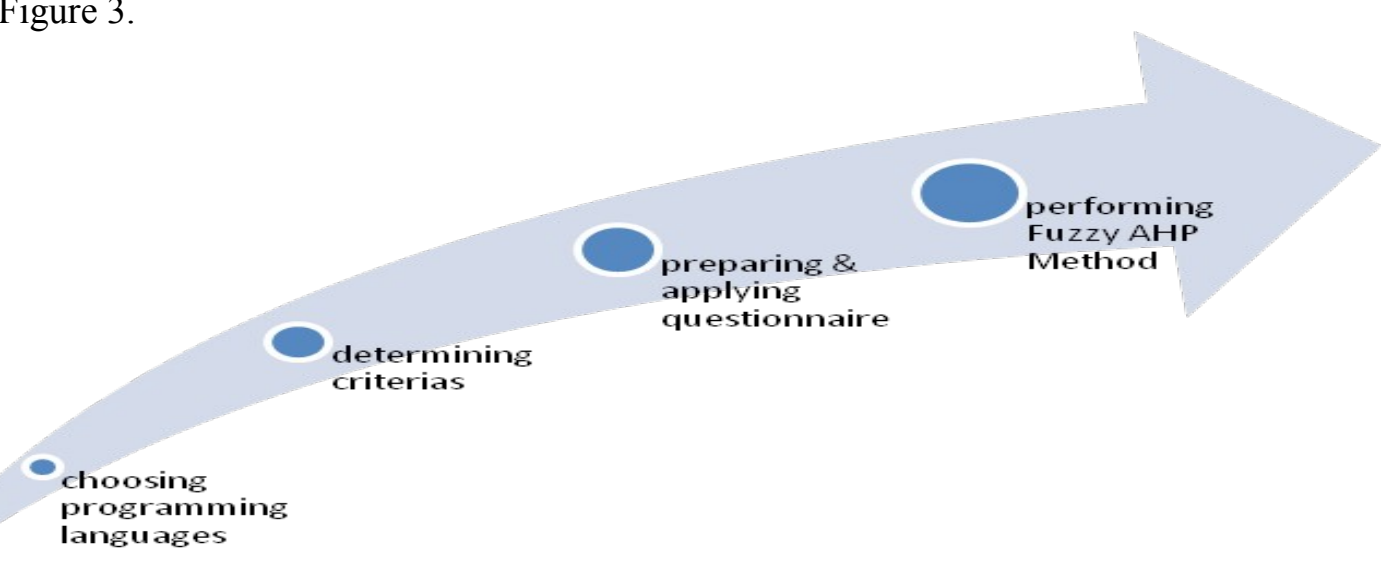

Figure 3: Steps of performing Fuzzy AHP Method for Language Selection.

The first step in the application is the determination of the purpose, criterions and alternatives together with the schematic view of the problem. There are eight criterions. Hierarchy model showing these criterions and alternatives together are as in Figure 4.

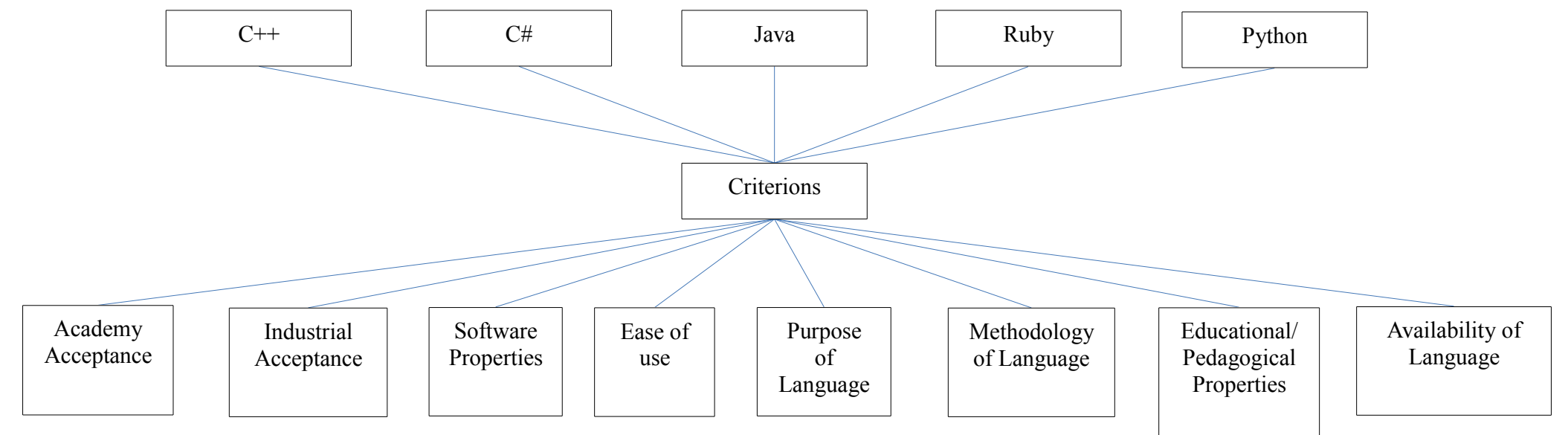

Figure 4: Criterions \&Alternatives.

International Symposium of the Analytic Hierarchy

Process
11

Washington, D. C. June 29 - July 2, 2014 
These criterions are explained briefly below.

Academic Acceptance: It is related with finding software language books, student or academic versions of programming languages.

Industrial Acceptance: It is related with usage in business world, choice of language is performed according to the employers' request.

Software Properties: It is related with system requirements, open source coding and operating system independence.

Ease of use: It is related with easy to use application development environment and easy to find errors.

Purpose of Language: It is related with development of web-based applications and some specific applications.

Methodology of Language: It is related with understanding and interpretations of expressions.

Educational/Pedagogical Properties: It is related with simplicity of basis expressions, security of coding.

Ability of Language: It is related with accessing people or tools who can support and qualified instructors

\section{Conclusions}

In this study we introduced FAHP method with the selection of object-oriented programming language. FAHP is a useful approach for evaluating complex multiple criteria alternatives involving subjective and uncertain judgment. The integration of FAHP approaches enables experts and students to efficiently select a more suitable object-oriented programming language for specific purpose and requirements. Our model's results are shown in Table 2.

Table 2. Results.

\begin{tabular}{|c|c|c|}
\hline Alternatives & Scores & Ranking \\
\hline C ++ & 0.033832 & 4 \\
\hline C\# & 0.037680 & 3 \\
\hline Java & 0.024202 & 5 \\
\hline Ruby & 0.076489 & 2 \\
\hline Python & 0.120546 & 1 \\
\hline
\end{tabular}


As seen in Table 2, Python programming language is the best one. Python is a generalpurpose high-level programming language whose design philosophy emphasizes code readability. Python supports multiple programming paradigms, primarily but not limited to object-oriented, imperative and, to a lesser extent, functional programming.

After the Python, Ruby takes second place, C\# takes third place, $\mathrm{C}++$ takes fourth place and Java takes fifth place.

FAHP combines the qualitative analysis with quantitative analysis to make subjective estimates more objective. The difficulties of fuzzy and proper weight distribution are overcome by FAHP, so that it ensures the status and importance of factors and makes the results more actual.

\section{Key References}

Christer Carlsson, \& Robert Full'er, (1996). Fuzzy multiple criteria decision making. Recent developments, Fuzzy Sets and Systems, 78, 139-153.

Cheng-Ru Wu, \& Che-Wei Chang, (2008). A Fuzzy ANP-based Approach to Evaluate Medical Organizational Performance, Information and Management Sciences, 19(1), 5374.

Erdebilli (B.D.Rouyendegh) B. (2011), Selecting the high - performing departments within universities applying the fuzzy MADM methods, Scientific Research and Essays (SRE) , 6, 2646-2654

Laarhoven, P. K. M., \& Pedrycz, W. (1983), A Fuzzy Extention of Saaty's Priority Theory, Fuzzy Sets and System, 11, 229-241.

Fong-Gong Wu, F.G., \& Ying-Jye Lee, Y.J., \& Ming-Chyuan Lin, C.M. (2004), Using the Fuzzy Analytic Hierarchy Process on Optimum Spatial Allocation, International Journal of Industrial Ergonomics, 33, 553-569.

Hsieh, T. Y., \& Lu, S. T., and Tzeng, G. H. (2004), Fuzzy MCDM Approach for Planning and Design Tenders Selection in Public Office Buildings, International Journal of Project Managmenet, 22, 573-584.

Mikhailov, L. (2003), Deriving Priorities from Fuzzy Pairwise Comparison Judgments, Fuz. Set. Sys., 134, 365-385.

Amy Lee, H.I., \& He-Yau Kang, \& Chang-Fu Hsu, \& Hsiao-Chu Hung (2009), A gren supplier selection model for high-tech industry, Expert Systems with Applications, 36(4), 7917-7927.

Chen, Y., \& Qu, L. (2006), Evaluating the Selection of Logistics Centre Location Using Fuzzy MCDM Model Based on Entropy Weight, Proceedings of the 6th World Congress on Intelligent Control and Automation, June 21 - 23, Dalian, China. 
Amy Lee, H.I., \& He-Yau Kang, \& Ching-Ter Chang (2009), Fuzzy multiple goal programming applied to TFD-LCD supplier selection by downstream manufacturers, Expert Systems with Applications, 36(3), 6318-6325.

Dagdeviren, M., \& Yuksel, I., (2008), Developing a Fuzzy Analytic Hierarchy Process (AHP) Model for Behavior-based Safety Management, Information Sciences, Vol. 178, No. 6, 1717-1733.

Subburaj Nagahanumaiah, \& Ravi, K.B. (2008), Computer Aided Rapid Tooling Process Selection and Manufacturability Evaluation for Injection Mold Development, Computers in Industry, Vol. 59 (2), (3), 262-276.

Duran, O., \& Aguilo, J. (2008), Computer-aided Machine-tool Selection Based on A Fuzzy-AHP Approach, Expert Systems with Applications, Vol. 34, No. 3, 1787-1794.

Felix, T.S., \& Chan, \& Niraj Kumar (2009), Global supplier development considering risk factors using fuzzy extended AHP-based approach, Omega, 35 (4), 417-431.

Yang, J. L., \& Chiu, H. N., \& Tzeng, G. H. (2008), Vendor selection by integrated fuzzy MCDM techniques with independence and Interdependence, To appear in Information Sciences, Accepted manuscript.

Rostamzadeh, R., \& Sofian, S. (2011), Prioritizing effective 7Ms to improve production systems performance using fuzzy AHP and fuzzy TOPSIS, Expert Systems with Applications, 38(5), 5166-5177.

Cascales, M. S. G., \& Lamata, M. T. (2008), Fuzzy Analytical Hierarchy Process in Maintenance Problem, IEA/AIE 2008, LNAI 5027, 815-824.

(Cascales \& Lamata, 2008)

Buyukozkan, G., \& Feyzioglu, O., \& Nebol, E. (2008), Selection of the strategic alliance partner in logistics value chain, Int. J. Production Economics, Vol. 113, 148-158.

Jung, H. (2011), A fuzzy AHP-GP approach for integrated production-planning considering manufacturing partners, Expert Systems with Applications, 38(5), 58335840 .

Bottani, E., \& Rizzi, A. (2008), An adapted multi-criteria approach to suppliers and products selection-An application oriented to lead-time reduction, Int. J. Production Economics, Vol. 111, 763-781.

Ming-Tien Tsai., \& Hsueh-Liang Wu., \& Wen-Ko Liang. (2008), Fuzzy Decision Making for Market Positioning and Developing Strategy for Improving Service Quality in Department Stores, Quality \& Quantity, Vol. 42, Vol. 42, 303-319. 
Chen, M. F., \& Tzeng, G. H., \& Ding, C.G. (2008), Combining Fuzzy AHP with MDS In Identifying The Preference Similarity of Alternatives, Applied Soft Computing, Vol. 8, No. 1, 110-117.

Efendigil, T., \& Onut, S., \& Kongar, E. (2008), A holistic approach for selecting a thirdparty reverse logistic provider in the presence of vagueness, Computers \& Industrial Engineering, 54(2), 269-287.

Cheng-Ru Wu., \& Chin-Tsai Lin., \& Huang-Chu Chen. (2008), Integrated environmental assessment of the location selection with fuzzy analytical network process, Quality and Quantity, Online first.

Zaerpour, N., \& Rabbani, M., \& Gharehgozli, A. H., \& Tavakkoli-Moghaddam, R. (2008), Make-to-order or make-to-stock decision by a novel hybrid approach, Advanced Engineering Informatics, 22(2), 186-201.

Huang, C., \& Chu, C., \& P. Y., \& Y. H. (2008), Chiang, A fuzzy AHP application in government-sponsored R\&D project selection, Omega, Vol. 36, No. 6, 1038(15).

Xiaojun Wang., \& Chan Hing Kai., \& Rachel Yee, W.Y., \& Ivan Diaz-Rainey. (2011), A two-stage fuzzy AHP model for risk assessment of implementing gren intiatives in the fashion supply chain, International Journal of Production Economics, In Press 2011, Corrected Proof.

Lee, D., \& Lee, C., \& Pietrucha, M. T. (2008), Evaluation of driver satisfaction of travel information on variable message signs using fuzzy aggregation, Journal of Advanced Transportation, Vol. 42, No. 1, 5(18).

El-Baz Adel, M. (2011), Fuzzy performance measurement of a supply chain in manufacturing companies, Expert Systems with Applications, 38(6), 6681-6688.

Che-Wei Chang., \& Cheng-Ru Wu., \& Chin-Tsai Lin, \& Huang-Chu Chen. (2008), Evaluating and controlling silicon wafer slicing quality using fuzzy analytical hierarchy and sensitivity analysis, Int J Adv Manuf Technol Vol. 36, 322-333.

Chang, T. H., \& Wang, T.-C. (2008), Measuring the success possibility of implementing advanced manufacturing, Expert Systems with Applications.

Weck, M., \& Klocke, F., \& Schell, H., \& Rüenauver, E. (1997), Production Cycles Using The Extended Fuzzy AHP Method, European Journal of Operational Research, 100,(2), 351-366.

Kulak, O., \& Kahraman, C. (2005), Fuzzy Multi-Criterion Selection Among Transportation Companies Using Axiomatic Design and Analytic Hierarchy Process, Information Sciences, 170, 191-210. 
Kuo, R. J., \& Chi, S. C., \& Kao, S. S. (2002), A Decision Support System for Selecting Convenience Store Location Through Integration of Fuzzy AHP and Artificial Neural Network, Computers in Industry, in Press.

Cheng, C. H. (1996), Evaluating Naval Tactical Missile Systems by Fuzzy AHP Based on The Grade Value of Membership Function, European Journal of Operational Research, 96, 343-350.

Zhu, K. J., \& Jing, Y., \& Chang, D. Y. (1999), A Discussion on Extent Analysis Method and Applications of Fuzzy-AHP, European Journal of Operational Research, 116, 450456.

Cheng, C. H., \& Yang, K. L., \& Hwang, C. L. (1999), Evaluating Attack Helicopters by AHP Based on Linguistic Variable Weight, European Journal of Operational Research, $116,423-435$.

Saaty, L. T., \& Vargas, L.G. (2006), Decision Making With the Analytic Network Process, Spr. Sci, 1-23.

Wang, Y.M., \& Liu, J., \& Elhag, T.M.S. (2007), An integrated AHP-DEA methodology for bridge risk assessment, Comp. Ind. Eng, 1-13.

Bouyssou, D., \& Marchant, T., \& Pirlot, M., \& Perny, P., \& Tsoukias, A., \& Vincke, P. (2000), Evaluation Models: A Critical Perspective, Kluwer, Boston.

Boender, C. G. E., \& De Graan, J. G., \& Lootsma, F. A. (1989), Multicriteria Decision Analysis with Fuzzy Pairwise Comparisons, Fuzzy Sets and Systems, 29, 133-143.

Buckley (a), J. J. (1985), Alternatives Using Fuzzy Members, Fuzzy Sets and Systems, 15, 21-31.

Buckley (b), J. J. (1985), Fuzzy Hierarchical Analysis, Fuzzy Sets and Systems, 17, 233247.

Chang, D. Y. (1996), Applications of The Extent Analysis Method on Fuzzy- AHP, European Journal of Operational Research, 95, 649-655.

Laarhoven, P. J. M., \& Pedrycz, W. (1983), A Fuzzy Extension of Saaty's Priority Theory, Fuzzy Sets and Systems, 11, 229-241.

Lootsma, F. (1997), Fuzzy Logic for Planning and Decision-Making, Kluwer.

Ribeiro, R. A. (1996), Fuzzy Multiple Criterion Decision Making: A Review and New Preference Elicitation Techniques, Fuzzy Sets and Systems, 78, 155-181. 
Aşkın Ozdagoglu., \& Güzin Ozdagoglu. (2007), Comparıson of AHP and Fuzzy AHP for the Multıcriteria Decisıon Makıng Processes with Linguistic Evaluations, İstanbul Ticaret Üniversitesi Fen Bilimleri Dergisi Yll: 6 Sayl, 65-85. 